\title{
Use of sexed semen and female genotyping affects genetic and economic outcomes of Montbéliarde dairy herds depending on the farming system considered
}

\author{
Marie Bérodier, ${ }^{1,2 *}$ Mickaël Brochard, ${ }^{2,3}$ Didier Boichard, ${ }^{1}$ Charlotte Dezetter, ${ }^{4}$ Nathalie Bareille, ${ }^{5}$ \\ and Vincent Ducrocq ${ }^{1}$ \\ ${ }^{1} \mathrm{GABI}$, INRA, AgroParisTech, Université Paris-Saclay, 78350 Jouy-en-Josas, France \\ ${ }^{2} \mathrm{MO3}, 01250$ Ceyzériat, France \\ ${ }^{3}$ Umotest, 01250 Ceyzériat, France \\ ${ }^{4}$ Unité de Recherche sur les Systèmes d'Elevage (URSE), Ecole Supérieure d'Agricultures (ESA), Université Bretagne Loire, 55 rue Rabelais, \\ BP 30748, 49007 Angers Cedex, France \\ ${ }^{5}$ BIOEPAR, INRA, Oniris, 44307 Nantes, France
}

\section{ABSTRACT}

Genomic evaluation of cows and the use of sexed semen have recently provided opportunities for commercial dairy farmers to accelerate genetic progress at the herd level by increasing both selection accuracy and selection intensity. Because implementing genomic tests or using sexed semen generate extra costs, a higher investment capacity of the farm is required. In this study, we compared the effect of female genotyping alone or combined with the use of sexed semen on genetic and economic performance of the herds. Three typical Montbéliarde herds with different farming systems were considered: a 77-cow herd producing milk at a high price sold to make cheese with a protected designation of origin, a 60 -cow herd producing organic milk at a medium price sold for dairy, and a 120-cow herd producing standard milk at a lower price sold for dairy. Eight alternative scenarios were simulated over a 10-yr period for each herd, with combinations of the following: use (or not) of dairy sexed semen, use (or not) of beef breed semen, use (or not) of female genotyping at $15 \mathrm{~d}$ of age. A mechanistic, stochastic, and dynamic model was used to mimic the farmer's daily decisions and the individual cow's biology. Heifers (80\%) and first-lactation cows $(30 \%)$ that ranked highest on the French total merit index (France's national dairy index) were inseminated with sexed semen to ensure replacement and to maximize genetic gain, when sexed semen was used. During the $10 \mathrm{yr}$ of simulation, scenarios that included sexed semen (whether female genotyping was used or not) gained, on average, one extra year of

Received November 23, 2018.

Accepted June 27, 2019.

*Corresponding author: marie.berodier@inra.fr overall genetic gain over scenarios that did not include sexed semen. During the same period, scenarios that used female genotyping (whether sexed semen was used or not) gained, on average, 5 mo of overall genetic gain over scenarios using parent average only. The highest gains in net margin were always obtained when combining use of sexed semen with terminal crossbreeding. Maximum genotyping prices under which routine female genotyping is economically valuable (breakeven prices of genotyping) were under $€ 37$. Maximum genotyping prices, such that the female genotyping costs are refunded within $10 \mathrm{yr}$ of investment (investor genotyping price), were under €26. However, they would be higher over a longer period of use because genetic gain is cumulative. Because genotyping price is expected to decrease in the future, female genotyping will be worthwhile if combined with the use of sexed semen and beef breed semen.

Key words: dairy cattle, genomic selection, replacement and mating strategy, genetics, economic simulation

\section{INTRODUCTION}

Sexed semen is an attractive innovation for dairy cattle farmers. First, sexed semen provides the opportunity to secure replacements by creating a sex ratio bias (Hohenboken, 1999; Holden and Butler, 2018). Second, with the use of sexed semen on the best females, it is possible to inseminate genetically inferior cows with beef breed semen to produce terminal crossbred calves of higher economic value than dairy male calves (Ettema et al., 2017; Holden and Butler, 2018). Third, it limits calving difficulties associated with male calf birth in heifers at first calving (Norman et al., 2010; Holden and Butler, 2018). In 2009, a sexed semen laboratory was set up for the Montbéliarde breed. In 2011, genomic evaluations 
became routinely available in France for commercial females (Boichard et al., 2012). In addition to the accelerated genetic progress on the male pathway permitted by genomic selection, the combined use of female genomic testing and sexed semen offers an opportunity to increase both selection accuracy and intensity on the dam-cow pathway, and therefore to improve selection efficiency at the commercial herd level. Because implementing both these technologies generates extra costs, several studies have been conducted to assess the genetic and economic benefits of combining sexed semen and female genotyping in commercial dairy cattle herds. Genetic gain has been shown to increase when using sexed semen rather than conventional semen on heifers or first-lactation cows (Hjortø et al., 2015; Kaniyamattam et al., 2016; Ettema et al., 2017), when sexed semen was used preferentially on the genetically best females (Ettema et al., 2011) and when genetically inferior cows were excluded as a source of potential replacement heifers (Hjortø et al., 2015; Ettema et al., 2017; Johnson et al., 2018). In general, the more information is known about a female (pedigree, own performance), the less valuable it is to genomically test that female (Pryce and Hayes, 2012; Weigel et al., 2012; Newton et al., 2018). Therefore, female genotyping is usually recommended only for young female calves. In these studies, the economic impact of genetic gain was often considered fixed by assigning an economic value to one genetic standard deviation of the breeding goal and by calculating genetic gain separately from other incomes. This assumption comes down to considering an equal economic impact of genetic gain regardless of the pricing system. However, the economic benefit of using sexed semen, female genotyping, and terminal crossbreeding depends on the farming system and its environment, particularly on price assumptions for milk sales, animal sales, or rearing costs (McCullock et al., 2013; Ettema et al., 2017; Newton et al., 2018). Most studies assessing genetic and economic benefits of female genotyping combined with terminal crossbreeding and sexed semen considered Holstein cows bred in the most common feeding systems and producing milk sold to regular dairy factories. However, dual-purpose breeds such as the Montbéliarde in France are managed quite differently and are characterized by different average herd size, feeding system, milk price, and so on. Moreover, published studies usually assess the economic interest of female genotyping at equilibrium; for example, calculating a breakeven price of genotyping. In practice, during the first years of implementation of female genotyping, farmers have to invest extra money. Yet the benefits of more accurate genetic information on females may appear only after several years, when heifers start to calve and produce milk.
In this study, we compared the genetic and economic evolutions of a typical Montbéliarde herd, considering 3 farming systems after 10 yr of simulation under 8 alternative genotyping and replacement strategies. We also computed 2 key prices for female genotyping: a breakeven price of genotyping and a maximum genotyping price to obtain a nonnegative return on investment after $10 \mathrm{yr}$.

\section{MATERIALS AND METHODS}

\section{Overview of the Simulation Model}

To simulate Montbéliarde dairy herds, we used a mechanistic, stochastic, and dynamic model developed by ONIRIS-INRA Nantes and fully described by Dezetter et al. (2017). The model simulates the biology of each female of the herd on each day, mimicking biological laws (milk production, reproductive events, health status) and the management decisions of the farmer (reproduction and culling decision) that would be made in typical French Montbéliarde dairy herds in 2018. In the model, each female of the herd is represented by many variables that can be either fixed for her entire life (genetic values), updated daily (milk production, age), or when a particular event occurs (ovulation, fetus conception, calving, health disorder). Costs (e.g., insemination, mastitis treatment) and revenues (e.g., milk and animal sales) are recorded and aggregated at the end of each simulated year. Margin over variable cost is calculated from variable costs and revenues at the dairy operation level. An inflation rate of $1 \%$ (which was the average inflation rate in France from 2009 until 2018; INSEE, 2019) was applied to costs and revenues. In our study, we supposed that the overall structure of the farm remained constant (housing, milking stalls, labor, and roughage). Therefore, fixed costs do not vary and the variations in net margin are similar to the variations in margin over variable costs.

\section{Simulation Protocols and Timeline}

Three types of Montbéliarde dairy cattle herds were modeled: (1) a herd where milk is produced to make cheese under protected designation of origin (PDO cheese), hereafter "cheese"; (2) a herd producing organic milk sold to dairy, hereafter "organic"; and (3) a herd producing conventional milk sold to dairy, hereafter "milk." The data of these herds - in particular, herd size, feeding system, milk price, and animal pricewere obtained from the farming network INOSYS of the Institut de l'Elevage, France (idele.fr/services/ outils/observatoire-inosys-reseaux-delevage.html) and updated according to local experts (F. Dubief, MO3, 
Ceyzériat, France, personal communication). Overall and farming system-specific price assumptions are presented in Supplemental File S1 (https://doi.org/10 .3168/jds.2018-16041) and were assumed constant for the entire simulation. Within each farming system, 8 alternative scenarios were applied to each type of herd, which were combinations of the following: use (or not) of sexed semen (Sex, NSex) on heifers and primiparous cows, use (or not) of beef breed semen $(\mathbf{C r}, \mathbf{N C r})$ on multiparous cows, and use (or not) of female genotyping $(\mathbf{G}, \mathbf{P})$ at $15 \mathrm{~d}$ of age. Therefore, 24 protocols $(3$ $\times 8$ ), presented in Table 1 , were simulated, each with 250 replicates, for $15 \mathrm{yr}$. The first $5 \mathrm{yr}$ represent the initialization step ( $y r-4$ to yr 0 ), where the herd was managed with no female genotyping, no sexed semen, and no beef semen use. After the initialization step, the alternative scenarios were simulated for 10 more years (yr 1 to yr 10). As intensive use of sexed semen could lead to increasing fixed costs (e.g., labor, land), we also added a cost of $€ 1.5 / \mathrm{d}$ of life for each extra heifer reared (Delphine Bouilloux, UMOTEST, Ceyzériat, France, personal communication). This number of additional heifers alive in the herd results from the comparison with the number of heifers alive in the herd at yr 0 (reference year).

\section{Modeling Genetic Values at Conception}

Simulated Female. True genetic values of a dairy female calf were calculated at conception for 6 traits: milk yield (MY), fat content (FC), protein content (PC), cow conception rate (FER), female longevity (LONG), and udder health (UH). The sire was chosen stochastically at each insemination from a pool of 10 potential sires assumed to be unrelated to the cows. Sire and dam true breeding values (TBV) were used to calculate the TBV of the offspring as follows:

$$
T B V_{i, \text { offspring }}=T B V_{i, \text { sire }}+T B V_{i, d a m}+M S_{i},
$$

where $i$ is the $i$ th trait; $M S_{i}$ is the Mendelian sampling term drawn from a multivariate normal distribution $\operatorname{MVN}(\mathbf{0}, 1 / 2 \mathbf{G})$, where $\mathbf{G}$ is the $6 \times 6$ genetic co(variance) matrix between the traits considered. The EBV of the offspring depended on the TBV calculated using the above formula and the expected reliability (further details regarding the EBV calculation are available in Supplemental File S2; https://doi.org/10 .3168/jds.2018-16041). In scenarios where females were genotyped, reliabilities of genomic EBV (GEBV) were assumed to be $0.65,0.65,0.65,0.57,0.56$, and 0.65 for

Table 1. Short names and description of the scenarios tested

\begin{tabular}{|c|c|c|c|c|}
\hline Name $^{1}$ & $\begin{array}{l}\text { Farming } \\
\text { system }\end{array}$ & $\begin{array}{l}\text { Female genotyped } \\
\text { at } 15 \mathrm{~d} \text { of life }\end{array}$ & $\begin{array}{l}\text { Use of sexed } \\
\text { semen }\end{array}$ & $\begin{array}{l}\text { Use of beef } \\
\text { breed semen }\end{array}$ \\
\hline Che(P)NSex-NCr & Cheese & No & No & No \\
\hline Che(P)Sex-NCr & Cheese & No & Yes & No \\
\hline Che(P)Sex-Cr & Cheese & No & Yes & Yes \\
\hline Che (P) NSex-Cr & Cheese & No & No & Yes \\
\hline Che(G)NSex-NCr & Cheese & Yes & No & No \\
\hline Che(G)Sex-NCr & Cheese & Yes & Yes & No \\
\hline Che(G)Sex-Cr & Cheese & Yes & Yes & Yes \\
\hline Che(G)NSex-Cr & Cheese & Yes & No & Yes \\
\hline Org(P)NSex-NCr & Organic & No & No & No \\
\hline Org(P)Sex-NCr & Organic & No & Yes & No \\
\hline Org (P)Sex-Cr & Organic & No & Yes & Yes \\
\hline $\operatorname{Org}(\mathrm{P})$ NSex-Cr & Organic & No & No & Yes \\
\hline $\operatorname{Org}(\mathrm{G}) \mathrm{NSex}-\mathrm{NCr}$ & Organic & Yes & No & No \\
\hline Org(G)Sex-NCr & Organic & Yes & Yes & No \\
\hline $\operatorname{Org}(\mathrm{G})$ Sex-Cr & Organic & Yes & Yes & Yes \\
\hline $\operatorname{Org}(\mathrm{G})$ NSex-Cr & Organic & Yes & No & Yes \\
\hline $\mathrm{Mil}(\mathrm{P}) \mathrm{NSex}-\mathrm{NCr}$ & Milk & No & No & No \\
\hline $\operatorname{Mil}(\mathrm{P}) \mathrm{Sex}-\mathrm{NCr}$ & Milk & No & Yes & No \\
\hline $\operatorname{Mil}(\mathrm{P}) \mathrm{Sex}-\mathrm{Cr}$ & Milk & No & Yes & Yes \\
\hline $\operatorname{Mil}(\mathrm{P}) \mathrm{NSex}-\mathrm{Cr}$ & Milk & No & No & Yes \\
\hline $\operatorname{Mil}(\mathrm{G}) \mathrm{NSex}-\mathrm{NCr}$ & Milk & Yes & No & No \\
\hline $\operatorname{Mil}(G) \operatorname{Sex}-\mathrm{NCr}$ & Milk & Yes & Yes & No \\
\hline $\operatorname{Mil}(\mathrm{G}) \mathrm{Sex}-\mathrm{Cr}$ & Milk & Yes & Yes & Yes \\
\hline $\operatorname{Mil}(G) N S e x-C r$ & Milk & Yes & No & Yes \\
\hline
\end{tabular}

${ }^{1}$ Che = cheese system $;$ Org $=$ organic system; Mil = milk system; $\mathrm{P}=$ no female genotyping (pedigree based); $\mathrm{G}=$ female genotyping; NSex = no use of sexed semen; Sex = use of sexed semen; $\mathrm{NCr}=$ no crossbreeding with beef breed; $\mathrm{Cr}=$ crossbreeding with beef breed. 
MY, FC, PC, FER, LONG, and UH traits, respectively (Dezetter et al., 2017), which correspond approximately to the current reliability level of the GEBV of young Montbéliarde animals for those traits. Otherwise, the reliability coefficients used was 0.3 for all traits, which would roughly correspond to the reliability of pedigree index (PEBV) when the sire and maternal grandsire are well known. Animal performance was influenced by the TBV, as described by Dezetter et al. (2017). For instance, MY, FY, and PY were used as inputs to model the daily milk production and daily milk contents of each cow, partially based on Wood (1967) and Coulon et al. (1995); FER influenced the probability of fertilization of the oocyte at each insemination; LONG was one of the input parameters to calculate the culling score that determined the daily probability of being culled; and UH influenced the probability of having mastitis.

Sire Breeding Values. A breeding company provides frozen semen of bulls from outside the herd. Sires were modeled only through their breeding values. At insemination time of any cow, 1 bull was randomly chosen as sire from a pool of 10 bulls. Each simulated year, a pool of 10 bulls was randomly chosen from a larger set of 35 bulls to mimic the variability of bulls available to the breeders from one year to another. The set of 35 dairy bulls consisted of the 35 top young bulls for French total merit index in 2018, without daughter performance. They were selected based on their GEBV. In $y r-4$, the average total merit index value of the 35-bull group was 140 and the standard deviation was 13 total merit index units (the total merit index is expressed on a female base, centered on 100 with a standard deviation of 20). Their TBV were determined from a normal distribution $N\left(E B V_{i}, \sqrt{\left(1-r_{i}\right) \sigma_{i}^{2}}\right)$, where $i$ is the trait number, $r_{i}$ is the reliability for the $i$ th trait, and $\sigma_{i}^{2}$ is the genetic variance of the $i$ th trait. At the beginning of each simulated year, the bulls' EBV were updated to account for the genetic trend, $\Delta G_{j}$, of the Montbéliarde breed over the years on trait $j$ (Dezetter et al., 2017):

$$
E B V_{s, j, n}=E B V_{s, j, i n i t}+(n-1) \Delta G_{j},
$$

where $E B V_{s, j, n}$ is the EBV of sire $\mathrm{s}$ for trait $\mathrm{j}$ in year $\mathrm{n}$ after the beginning of the simulation and $E B V_{s, j, i n i t}$ is the EBV of sire $s$ for trait $j$ in the first simulated year. The annual genetic gains used to update the EBV were $52 \mathrm{~kg}$ for $\mathrm{MY}, 0.03 \mathrm{~g} / \mathrm{kg}$ for $\mathrm{FC}, 0.08 \mathrm{~g} / \mathrm{kg}$ for $\mathrm{PC}$, $0.02 \mathrm{SD}$ units for FER (equivalent to around $0.14 \%$ of conception rate), 0.06 SD units for LONG, and 0.03 SD units for UH (A. Launay, Idele, Paris, France, personal communication).
Total Merit Index. The French total merit index represents the animals' overall genetic profitability within the population. It is calculated as a linear combination of the animals' EBV reflecting the current situation. Weights of trait groups were $45 \%$ for overall production, $18 \%$ for overall reproduction, $14.5 \%$ for udder health, and $22.5 \%$ for functional traits (type traits, longevity, and milking speed). Because our model did not include all the traits that are part of the total merit index, new weights associated with the MY, FC, PC, FER, LONG, and UH traits were calculated by multiple linear regression of the total merit index on all these traits for all French Montbéliarde females genotyped from January 2013 to January 2018. In the simulation, the total merit index was calculated for each female, together with her other breeding values. Mating and culling decisions in the simulation were made based on this total merit index. For instance, heifers ranked in the bottom $20 \%$ for total merit were never inseminated with sexed semen.

\section{Modeling Mating Plans}

Design. In France, each year, Montbéliarde farmers determine how many females, among their best females, they have to inseminate with purebred semen to produce enough heifers for replacement. Our model was calibrated to replicate this practice: at the beginning of each simulated year, matings were planned for all the females that might be inseminated during the year. For instance, the bottom $20 \%$ of heifers and the bottom $70 \%$ of first-lactation cows on total merit index and cows in lactation 2 or more were never planned to be inseminated with sexed semen in the Sex-Cr or Sex-NCr scenarios. Along the simulated year, females were inseminated according to the planned matings. However, after 2 unsuccessful inseminations with sexed semen, farmers usually breed a heifer back with conventional semen. The models for Sex-Cr and Sex- $\mathrm{NCr}$ scenarios mimicked this behavior. In the Sex-Cr and Sex-NCr scenarios, first-lactation cows failing to conceive twice with sexed semen were bred back with conventional semen. In the Sex-Cr and NSex-Cr scenarios, cows that failed to conceive twice with conventional semen were bred back with beef breed semen. In the Sex-NCr and NSex-NCr scenarios, cows planned to be inseminated with conventional semen were sired with conventional semen until pregnant or culled. The model was calibrated so that the achieved proportions of sexed semen, conventional semen, and beef breed semen used with heifers and cows are the ones shown in Table 2. A voluntary waiting period for insemination after calving was set to $45 \mathrm{~d}$ with conventional semen and to $60 \mathrm{~d}$ with sexed semen, according to the farm- 
Table 2. Proportions of AI (\%; sexed semen, conventional semen, and beef breed semen) used in heifers and cows after calibration, depending on the replacement scenario $^{1}$

\begin{tabular}{lcccc}
\hline & \multicolumn{3}{c}{ Scenario } \\
\cline { 2 - 5 } Semen type and female category & NSex-NCr & Sex-NCr & NSex-Cr & Sex-Cr \\
\hline Sexed semen in heifers & 0 & 70 & 0 & 70 \\
Conventional semen in heifers & 100 & 30 & 100 & 30 \\
Sexed semen in cows & 0 & 10 & 0 & 5 \\
Conventional semen in cows & 100 & 90 & 90 & 55 \\
Beef breed semen in cows & 0 & 0 & 10 & 40
\end{tabular}

${ }^{1} \mathrm{NSex}=$ no use of sexed semen; $\mathrm{Sex}=$ use of sexed semen; $\mathrm{NCr}=$ no crossbreeding with beef breed; $\mathrm{Cr}=$ crossbreeding with beef breed.

ers' usual practices. Generally, farmers avoid mating heifers (whatever their breeding value) to beef breed bulls because of the higher risk of dystocia, which could negatively affect the entire productive life of the cow. Therefore, beef breed semen was never used on heifers in the simulations.

Reproduction. The probability of fertilization of the oocyte after insemination depends on several multiplicative factors (such as parity, milk production, number of cycles, or quality of estrus cycle) fully described in appendix A of Dezetter et al. (2017), and were adjusted to be in line with the Montbéliarde breed reproductive performance. To account for decreased fertility when using sexed semen compared with conventional semen, the probability of fertilization of an oocyte was multiplied by 0.95 (0.85) for a heifer (cow). This was in line with the observed decreased fertility when sexed semen is used in the Montbéliarde breed (Jean-Marc Vacelet, UMOTEST, Ceyzériat, France, personal communication). The sex of the embryo was triggered at fertilization. The ratio of female calves was assumed to be 0.5 with conventional semen and 0.9 with sexed semen (Le Mézec, 2016).

\section{Modeling Culling and Replacement Strategies}

All simulated herds were managed to maintain a fixed number of cows. They were not limited by the amount of milk they could sell to dairy nor the number of heifers they could raise. The "culling" module was called every $15 \mathrm{~d}$ to control the number of cows in the herd: if the maximum number of cows in the herd was reached, the total merit index of a heifer just before calving was compared with that of cows with more than 100 DIM. If the heifer belonged to the 30\% worst females for total merit index, she was sold as a heifer "ready to calve." Otherwise, she calved, entered the lactating herd, and triggered the culling of another cow. To mimic the culling choice of a farmer, the model calculated a culling probability score for each cow. This score is a combination of several criteria considering within-herd daily milk production, fat and protein contents, udder health status, reproductive status, global health status, and phenotypic longevity. The simulation program randomly culled one of the $35 \%$ "top candidates to culling" according to their culling probability score. This procedure was repeated until the maximum number of cows in the herd was reached again.

\section{Statistical Analyses}

General. Each year, the true genetic merit of the animals, their performance, incomes, and outcomes were recorded per herd and averaged per scenario. Results for yr 0 give a good picture of herds for each farming system before the alternative strategies were applied. Whenever possible, to allow for comparisons between different farming systems of different herd sizes, output statistics were calculated per cow-herd in a year, which is the average number of cows present in the herd per year. It was calculated as the sum of cows present each day in the herd divided by the number of days in a year. For each herd, breeding values of cows present in the herd the last day of the simulated year were averaged. Output statistics were calculated using $\mathrm{R}$ version 3.5.1 ( $\mathrm{R}$ Core Team, 2018) and average differences in output statistics from yr 0 to yr 10 across scenarios were calculated using the package "emmeans" (Lenth, 2018).

Genotyping Prices. When starting female genotyping, we assumed that farmers only genotyped young heifers and not the entire herd as they are advised to do. Consequently, a transition period existed in which the herd was composed of females selected on GEBV and females selected on PEBV. After $8 \mathrm{yr}$ of alternative replacement strategies including genotyping, almost all cows that were present in the herd in yr 0 had been replaced by females selected on their GEBV and a routine began to emerge. We defined the breakeven price of genotyping as the maximum genotyping price under which routine female genotyping is economically valuable. Therefore, the breakeven price of genotyping 
was calculated by comparing the margin in scenarios using and not using female genotyping, in yr 9 and 10 (Equation [3]):

$$
\text { Genotyping price }=\frac{N M(j)_{9 \& 10}-N M(i)_{9 \& 10}}{n_{-} \text {geno }},
$$

where $j$ is a strategy using female genotyping, $i$ is the strategy without female genotyping, $N M(j)_{9 \& 10}$ or $N M(i)_{9 \& 10}$ is the net margin per cow of scenario $j$ or $i$ in yr 9 and 10, respectively, and $n \_g e n o$ is the number of genotyping tests per cow performed in yr 9 and 10 in strategy $j$.

Furthermore, we looked at female genotyping from an investor point of view using a discount rate of $4 \%$. Female genotyping is a particular type of investment because the investment needs to be repeated yearly and the benefits obtained from genotyping are distributed over time (each lactation of the selected females). For instance, females genotyped in yr 10 do not bring any economic advantage in yr 10; rather, the benefit of those female genomic tests will start to appear $2.5 \mathrm{yr}$ later, when females selected on GEBV start to produce milk. Therefore, a maximum "investor price" was calculated. This investor genotyping price is the maximum genotyping price such that the costs due to female genotyping are refunded after $10 \mathrm{yr}$ of simulation through the better performance (milk production, fertility, and health) of the females selected on their GEBV, compared with the same replacement strategy using only PEBV. When female genotyping cannot refund the investment within $10 \mathrm{yr}$ of simulation under the replacement strategy considered, no investor genotyping price can be calculated.

The maximum investor genotyping price was calculated, for each replacement strategy and all farming systems, from the return on investment (ROI) in yr 10:

$$
\text { ROI }=\frac{\text { Net profit }}{\text { Total investment }}=\frac{\text { Profit }- \text { total investment }}{\text { Total investment }} .
$$

The maximum investor genotyping price is the genotyping price for which the ROI is superior or equal to zero on $\mathrm{yr} 10$. It is the solution of the following equation:

$$
\frac{\sum_{1}^{10}\left[\mathrm{NM}(\mathrm{GEBV})_{n}-\mathrm{NM}(\mathrm{PEBV})_{n}\right]-\sum_{1}^{10} \mathrm{Adj}_{\text {geno. } \operatorname{costs}_{n}}}{\sum_{1}^{10} \text { Adj. geno. } \operatorname{costs}_{n}}=0,
$$

where $\mathrm{NM}(\mathrm{GEBV})_{n}$ is the discounted net margin of year $n$ for the strategy with female genotyping at an assumed genotyping cost of $€ 0 ; \mathrm{NM}(\mathrm{PEBV})_{n}$ is the discounted net margin of year $n$ for the same strategy without female genotyping; and Adj. geno. $\operatorname{costs}_{n}$ are the genotyping costs of year $n$ adjusted for the number of lactations performed by cows in the herd until yr 10 . Further details regarding adjusted genotyping costs calculation are provided in Supplemental File S3 (https:/ /doi.org/10.3168/jds.2018-16041).

\section{RESULTS}

\section{Structure of the Herd and Cow Performance}

Initial Herds. Table 3 presents the main characteristics of the 3 farming systems simulated (cheese, organic, and milk), at the end of yr 0 (end of the initialization step). Their characteristics are similar to typical French Montbéliarde dairy herds in 2017 according to local experts (F. Dubief, MO3 staff, Ceyzériat, France, personal communication). Until the end of yr 0 , all herds were managed with no female genotyping, no use of sexed semen, and no use of beef breed semen. Alternative strategies started on the first day of yr 1 .

Demography. After 10 yr of simulation, the average cow age was lower than at yr 0 for all strategies and all farming systems (Figure 1). The effects of female genotyping and replacement strategies on the demographic evolution of the herd were similar across the farming systems simulated: the number of females in lactation 5 and more decreased, whereas the number of females with fewer lactations increased over the 10 yr for all scenarios. Replacement rate and average age of cows were not affected by the use of female genotyping for a given replacement strategy and farming system (Figure 1). The main factor affecting the demographic structure of the herd was the replacement strategy, particularly the use of sexed semen without terminal crossbreeding (Sex-NCr). The latter replacement strategy increased replacement rate $(+6$ to +10 percentage points in 10 yr) and significantly decreased the average age of cows (around 4 mo younger than for other replacement strategies, Figure 1). Furthermore, the number of heifers almost doubled after $10 \mathrm{yr}$ of Sex-NCr strategy (results not shown). This larger number of heifers, combined with the replacement policy, explains why more heifers entered the herd and induced more cullings. Additional details regarding milk yield per cow and number of calves born in the herd are available in Supplemental File S4; https://doi.org/10.3168/jds.2018-16041). In brief, milk yield per cow and number of calves born in the herd were higher in yr 10 than in yr 0 for all replacement strategies and all farming systems.

Genetic Merit. In all 3 farming systems, the average genetic gain of the lactating herd (measured as gain in total merit index) did not differ across different genotyping and breeding strategies until after yr 3 . The 
Table 3. Herd demography and technical performances under the 3 farming systems ${ }^{1}$ simulated after initialization (end of yr 0) and before applying alternative mating and replacement strategies

\begin{tabular}{|c|c|c|c|c|}
\hline Item & Cheese & Organic & Milk & $\mathrm{SEM}^{2}$ \\
\hline \multicolumn{5}{|l|}{ Demography (head) } \\
\hline Heifers $0-1$ yr & 38 & 31 & 59 & \\
\hline Heifers $>1$ yr & 56 & 43 & 81 & \\
\hline First-lactation cows & 22 & 18 & 37 & \\
\hline Second-lactation cows & 19 & 14 & 27 & \\
\hline Third-lactation cows & 12 & 10 & 18 & \\
\hline Fourth-lactation cows & 8 & 7 & 14 & \\
\hline Cows in lactation 5 and more & 16 & 10 & 25 & \\
\hline Cow-herd in a year ${ }^{3}$ & 78 & 61 & 121 & \\
\hline \multicolumn{5}{|l|}{ Performance } \\
\hline Milk yield (L/cow per year) & 6,211 & 6,183 & 6,991 & 5.09 \\
\hline Average age (d) & 1,860 & 1,849 & 1,914 & 1.09 \\
\hline Heifer pregnancy rate after first insemination (\%) & 66.8 & 66.7 & 66.9 & 0.10 \\
\hline Cow pregnancy rate after first insemination (\%) & 45.7 & 45.7 & 44.2 & 0.07 \\
\hline Annual culling rate (\%) & 31.4 & 33.6 & 30.5 & 0.07 \\
\hline Annual replacement rate $(\%)$ & 33.7 & 34.1 & 29.4 & 0.07 \\
\hline
\end{tabular}

results for the cheese farming system are illustrated in Figure 2. Similar results were obtained for the organic and milk farming systems (results not shown). For all scenarios and all farming systems, genetic gain was higher (not always significantly) when using GEBV than PEBV to select and mate females (Figure 3). The effect of the strategy on the evolution of the genetic merit of the herd over $10 \mathrm{yr}$ of simulation was similar across the farming systems. On average, scenarios using female genotyping (GEBV) gained 0.07 SD of the total merit index over scenarios using parent average only (PEBV), in $10 \mathrm{yr}$ of simulation. For all farming systems, the genetic gain was always higher when using sexed semen than when using conventional semen (Figure 3). On average, scenarios using sexed semen gained 0.19 SD of the total merit index over scenarios using conventional semen, in $10 \mathrm{yr}$ of simulation.

Finally, genetic gain on the MY trait after $10 \mathrm{yr}$ of simulation (data not shown) induced a higher milk production per cow in yr 10 compared with yr 0 in all strategies and all farming systems, even though the age profile of the herd decreased (see Supplemental File S4 for more details; https://doi.org/10.3168/jds.2018 -16041).

Financial Performance. Whatever the farming system considered, the use of either PEBV or GEBV had no significant effect on variations in total revenues per cow for a given replacement strategy except for Sex-NCr in the organic system, where the GEBV was significantly higher than the PEBV strategy. The largest gain in total revenues over $10 \mathrm{yr}$ was reached for scenario Sex-NCr in all farming systems (Figure 3).
The variation in total revenues per cow can be divided into 3 parts: variations in milk sales, female sales (heifers and cows), and calf sales (see Supplemental File S4 for detailed results per category; https://doi.org/10 .3168/jds.2018-16041). Milk sales explained most of the change in total revenues from yr 0 to yr 10. However, different replacement strategies led to different levels of changes in animal sales: the smallest change was reached with scenario NSex-Cr and the highest with scenario Sex-NCr.

In scenario Sex-NCr, the increase in the value of female sales was much higher than the loss in calf sales. The highest increase in calf sales per cow was always obtained for Sex-Cr replacement scenarios, which were the scenarios producing the largest number of crossbred calves and the fewest purebred male calves.

Over $10 \mathrm{yr}$ of alternative replacement strategies, the total expenses per cow increased significantly more (except for cheese Sex-Cr, organic Sex-Cr, and organic NSex-Cr) when genotyping females compared with the equivalent scenarios not using female genotyping in all farming systems (Figure 4). Scenarios with Sex-NCr replacement strategy had the highest genotyping cost per cow (see Supplemental File S4; https://doi.org/10 .3168/jds.2018-16041).

Comparing farming systems, the change in net margin per cow over $10 \mathrm{yr}$ was the highest for the cheese farming system, whereas the average increase in net margin per cow was similar for the organic and milk farming systems. In the cheese and organic farming systems, the use of female genotyping did not affect the gain in net margin per cow (except for organic Sex-NCr). In the 


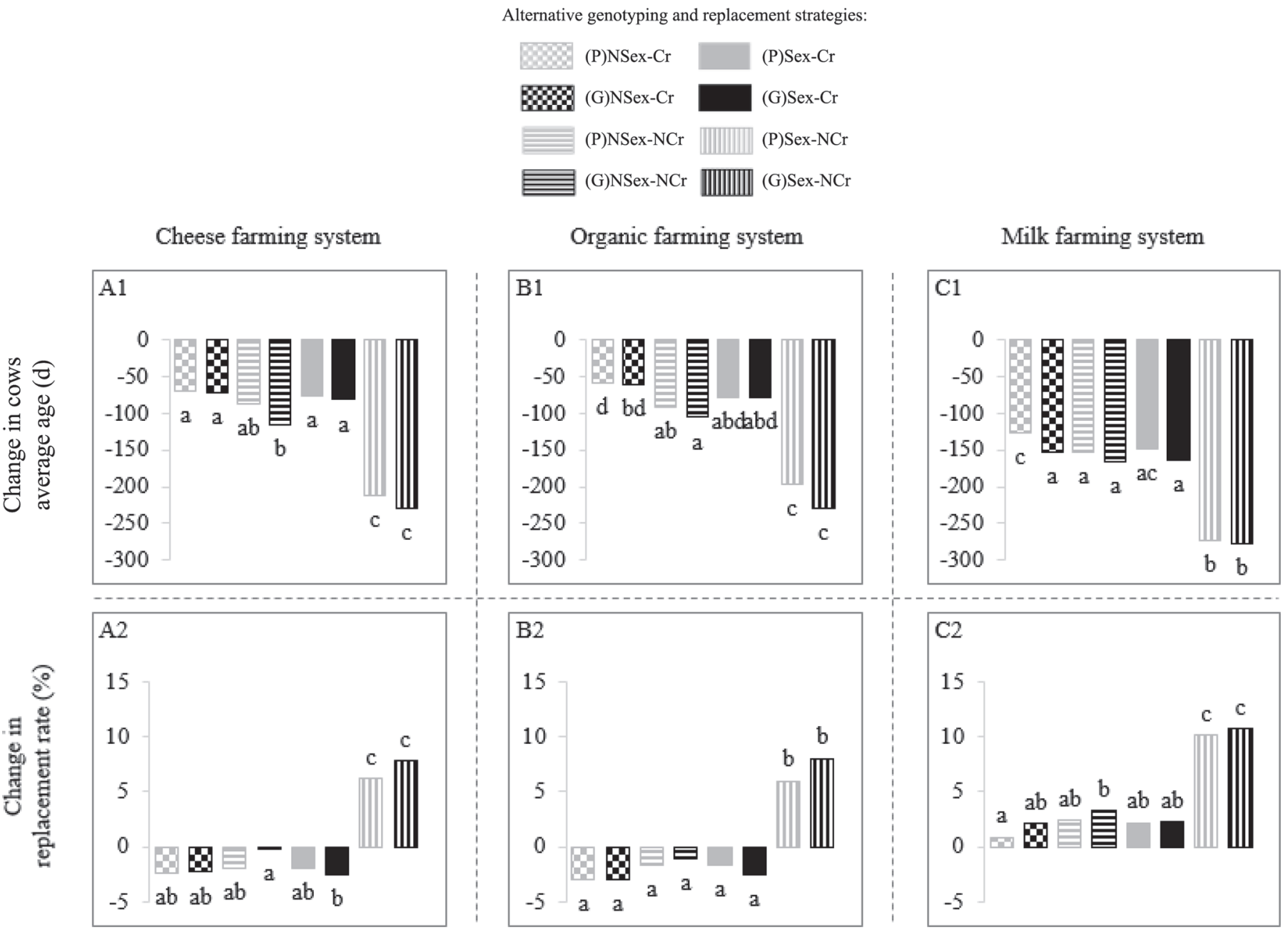

Figure 1. Change (year 10 values minus year 0 values) in average age of the cows $(\mathrm{A} 1, \mathrm{~B} 1$, and $\mathrm{C} 1$ ) and average replacement rate (A2, B2, and C2). Year 0 is the reference year with no use of female genotyping, sexed semen, or terminal crossbreeding; year 10 is the last simulated year after $10 \mathrm{yr}$ of alternative replacement and genotyping strategy. Averages were calculated over 250 simulation replicates per farming system and per alternative replacement and genotyping strategy. Farming system: Cheese farming system = milk sold to make protected designation of origin cheese (A1 and A2); Organic farming system = organic milk sold to dairy (B1 and B2); Milk farming system = standard milk sold to dairy (C1 and $\mathrm{C} 2$ ). Alternative replacement and genotyping strategies: $(\mathrm{P}) \mathrm{NSex}-\mathrm{Cr}=$ no female genotyping, conventional and beef breed semen only; $(\mathrm{G}) \mathrm{NSex}-\mathrm{Cr}=$ female genotyping, conventional and beef breed semen only; (P)NSex-NCr = no female genotyping, conventional semen only; (G) $\mathrm{NSex}-\mathrm{NCr}=$ female genotyping, conventional semen only; $(\mathrm{P}) \mathrm{Sex}-\mathrm{Cr}=$ no female genotyping, sexed, conventional, and beef breed semen; (G) $\mathrm{Sex}-\mathrm{Cr}=$ female genotyping, sexed, conventional, and beef breed semen; $(\mathrm{P}) \mathrm{Sex}-\mathrm{NCr}=$ no female genotyping, sexed and conventional semen only; and $(\mathrm{G}) \mathrm{Sex}-\mathrm{NCr}=$ female genotyping, sexed and conventional semen only. Bars with different letters $(\mathrm{a}-\mathrm{d})$ differ significantly $(P<0.05)$.

milk farming system, except for the Sex-Cr scenario, female genotyping led to a smaller gain in net margin compared with the equivalent scenario without female genotyping. The highest gain in net margin was always reached for Sex-Cr scenarios in all farming systems and the smallest for Sex-NCr scenarios because of the increase in workload associated with more heifers reared.

\section{Genotyping Prices}

Table 4 displays genotyping breakeven prices and maximum investor prices for each of the 4 replacement strategies tested within each farming systems. In all farming systems, the highest breakeven prices were reached for the Sex-Cr strategy. The Sex-NCr scenario from the organic farming system and NSex-Cr scenario from the milk farming system had negative breakeven genotyping prices.

The genotyping breakeven price was higher in the cheese and organic farming systems (with high animal and milk prices) than in the milk farming system (characterized by farmers receiving a lower price for milk sales).

Maximum investor price was the highest for the Sex$\mathrm{NCr}$ strategy in the cheese farming system, the Sex-Cr strategy for the organic system, and the NSex-NCr 
strategy for the milk farming system. No maximum investor price could be calculated for the NSex-NCr and the Sex-NCr strategies for the organic farming system and the NSex-Cr strategy for the milk farming system. For the Sex-NCr and the NSex-NCr strategies in the cheese farming system and the NSex-NCr strategy in the milk farming system, the maximum investor price was higher than the breakeven price.

\section{DISCUSSION}

The aim of our study was to compare the effects of alternative genotyping and replacement strategies on herd structure, genetic gain, and animal and economic performance under 3 farming systems. The main differences between the 3 farming systems simulated were the price assumptions (see Supplemental File S1, Table

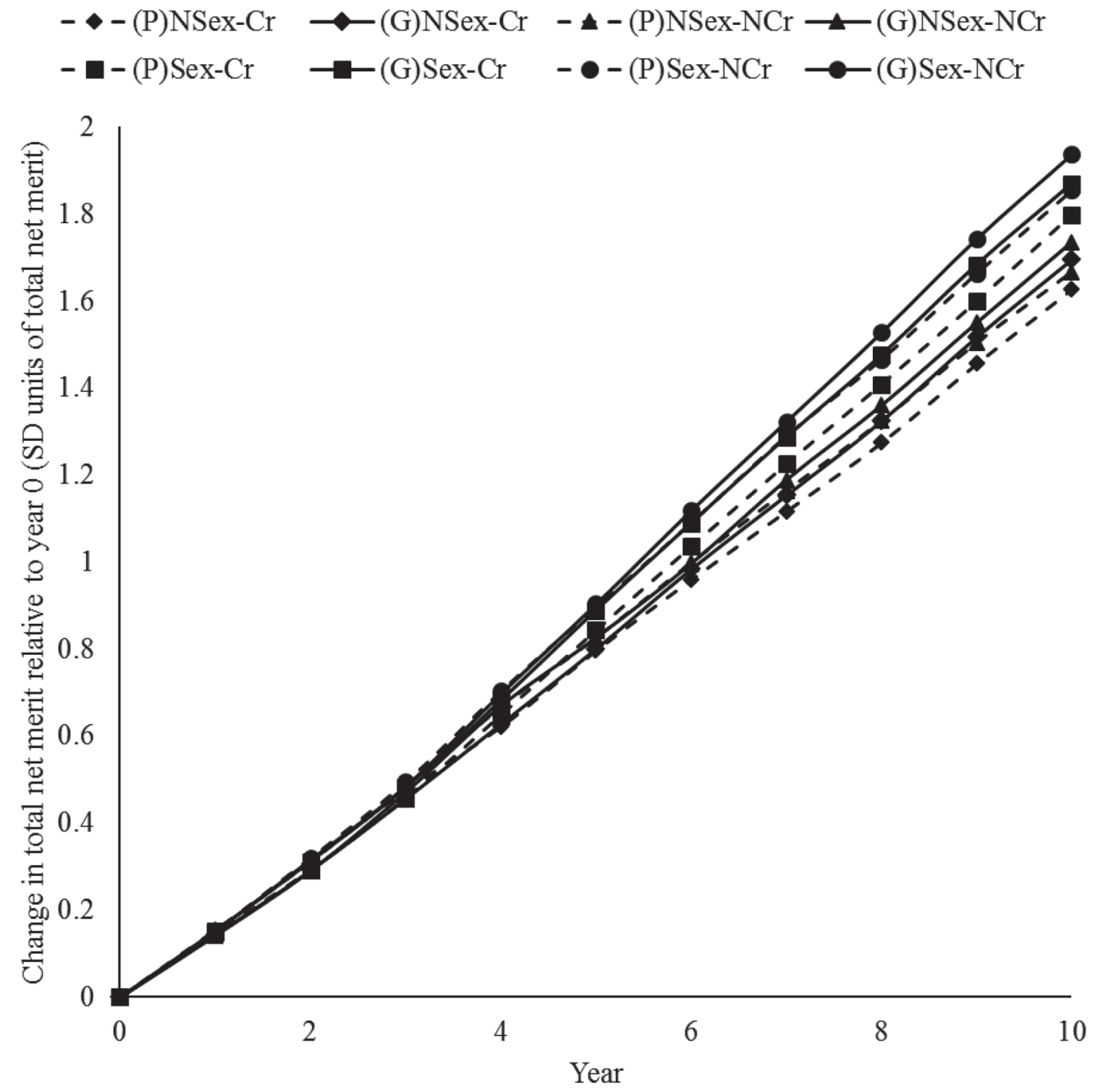

Figure 2. Change in average total merit index of the lactating herd in standard deviation units relative to year 0 (year $\mathrm{x}$ value minus year 0 value). Year 0 is the reference year with no use of female genotyping, sexed semen, or terminal crossbreeding; year 10 is the last simulated year after $10 \mathrm{yr}$ of alternative replacement and genotyping strategy. The average total merit index of the lactating herds was calculated over 250 simulations per alternative replacement and genotyping strategy (under the Cheese farming system; milk sold to make protected designation of origin cheese). Alternative replacement and genotyping strategies: $(\mathrm{P}) \mathrm{NSex}-\mathrm{Cr}=$ no female genotyping, conventional and beef breed semen only; (G)NSex-Cr = female genotyping, conventional and beef breed semen only; (P)NSex-NCr = no female genotyping, conventional semen only; (G) NSex-NCr = female genotyping, conventional semen only; $(\mathrm{P}) \mathrm{Sex}-\mathrm{Cr}=$ no female genotyping, sexed, conventional, and beef breed semen; (G) Sex-Cr $=$ female genotyping, sexed, conventional, and beef breed semen; $(\mathrm{P}) \mathrm{Sex}-\mathrm{NCr}=$ no female genotyping, sexed and conventional semen only; and (G)Sex-NCr = female genotyping, sexed and conventional semen only. 
S2; https://doi.org/10.3168/jds.2018-16041) and herd size (Table 3), which affected the revenues from animal products and the potential benefit of using genotyping, sexed semen, or terminal crosses.

\section{Limits of the Simulation Model}

Potential Applications of Female Genotyping. Our model considers simplified mating plans limited to the choice among 3 categories of semen for each female to be inseminated. However, when farmers choose to genotype their young Montbéliarde heifers in France, they usually use this information at mating, being careful to maximize genetic gain on several traits, while correcting major defects or avoiding matings between carriers of the same genetic defects, or both. Therefore, higher genetic gains in commercial farms using heifer genotyping can be anticipated compared with those reported in our study. Other benefits of female genotyping, such as reduced pedigree errors or better control of inbreeding at mating (Pryce and Hayes, 2012), were not accounted for in our simulation model. Yet they could
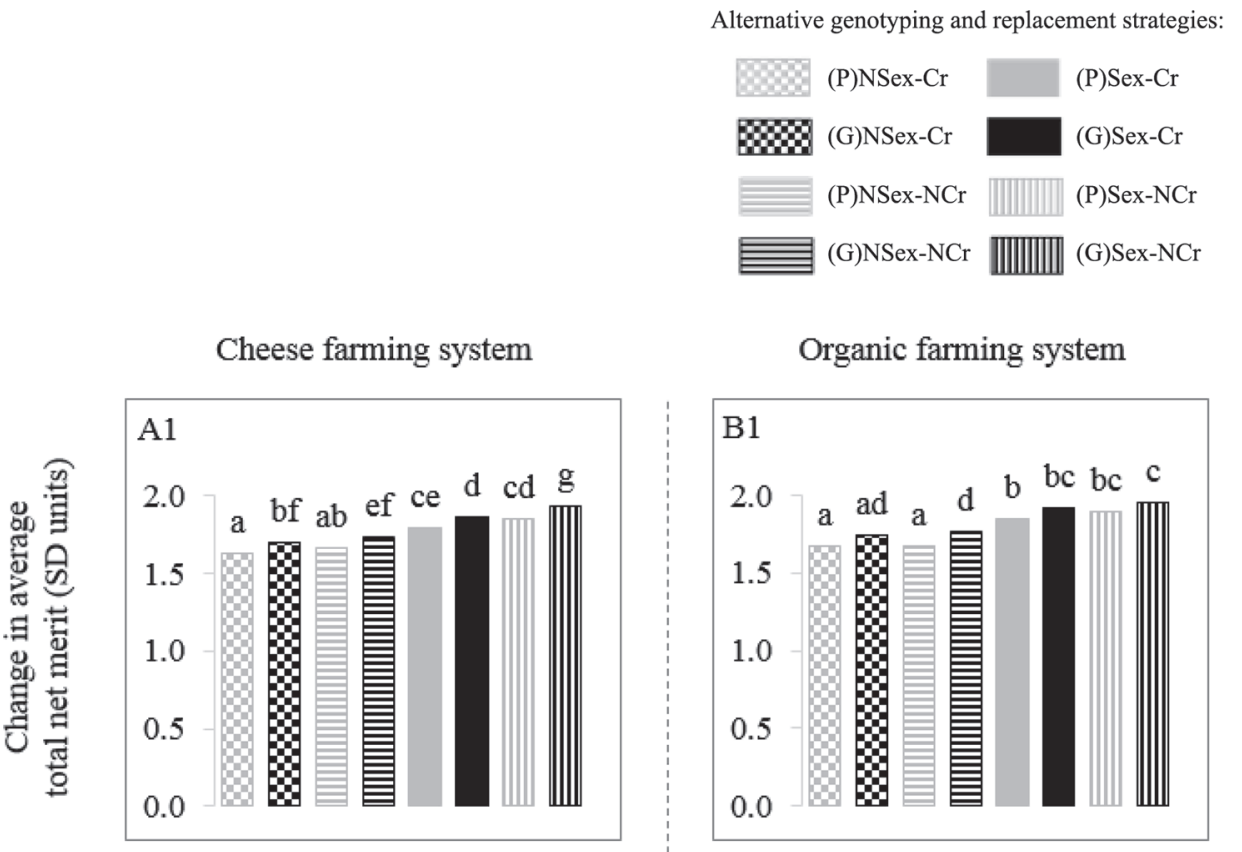

\section{Milk farming system}
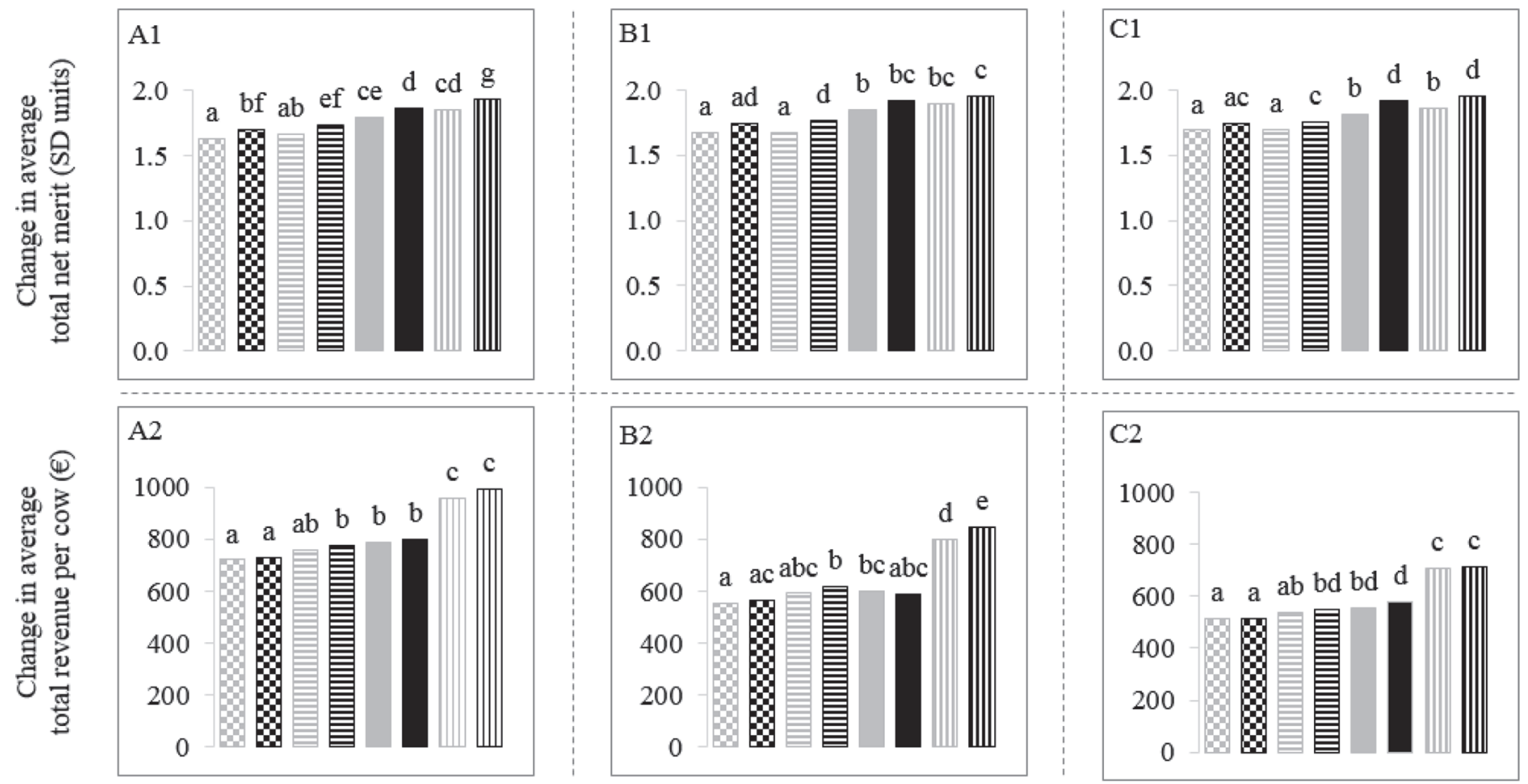

Figure 3. Change (year 10 values minus year 0 values) in average total merit index of the lactating herd (A1, B1, and C1) and average total revenue per cow (A2, B2, and C2). Year 0 is the reference year with no use of female genotyping, sexed semen, or terminal crossbreeding; year 10 is the last simulated year after $10 \mathrm{yr}$ of alternative replacement and genotyping strategy. Averages were calculated over 250 simulation replicates per farming system and per alternative replacement and genotyping strategy. Farming system: Cheese farming system $=$ milk sold to make protected designation of origin cheese (A1 and A2); Organic farming system = organic milk sold to dairy $(\mathrm{B} 1$ and B2); Milk farming system $=$ standard milk sold to dairy ( $\mathrm{C} 1$ and $\mathrm{C} 2)$. Alternative replacement and genotyping strategies: (P)NSex-Cr = no female genotyping, conventional and beef breed semen only; (G)NSex-Cr = female genotyping, conventional and beef breed semen only; $(\mathrm{P}) \mathrm{NSex}-\mathrm{NCr}=$ no female genotyping, conventional semen only; (G)NSex-NCr = female genotyping, conventional semen only; (P)Sex-Cr = no female genotyping, sexed, conventional, and beef breed semen; (G)Sex-Cr = female genotyping, sexed, conventional, and beef breed semen; (P)Sex-NCr = no female genotyping, sexed and conventional semen only; and $(\mathrm{G}) \mathrm{Sex}-\mathrm{NCr}=$ female genotyping, sexed and conventional semen only. Bars with different letters (a-g) differ significantly $(P<0.05)$. 
improve the economic benefit of female genotyping in commercial herds.

Genotyping Age. For simplicity in our simulations, all young heifers were genotyped at $15 \mathrm{~d}$ old, which is not exactly what farmers would do; they usually genotype later to reduce the risk of genotyping heifers that might die or be culled before reaching reproductive age. The cost of unnecessary genomic tests could be saved, hence reducing overall farm costs. Therefore, we expect the genotyping breakeven price to be higher in reality than what we found in our study.
Sexed Semen Assumptions. An additional direction that was not considered in this study is varying the proportions of animals bred to each type of semen (sexed, conventional, and beef breed semen) as in Hjortø et al. (2015). However, their highest breakeven prices were obtained with proportions of use of sexed semen in the range of what we tested. In our study, we considered an average Montbéliarde herd regarding reproductive performance and the impact of sexed semen on the probability of oocyte fertilization was fixed, yet conception rate with sexed semen can vary in the

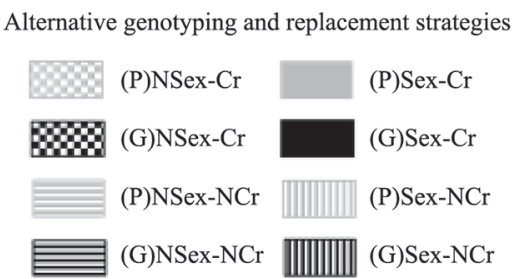

Cheese farming system
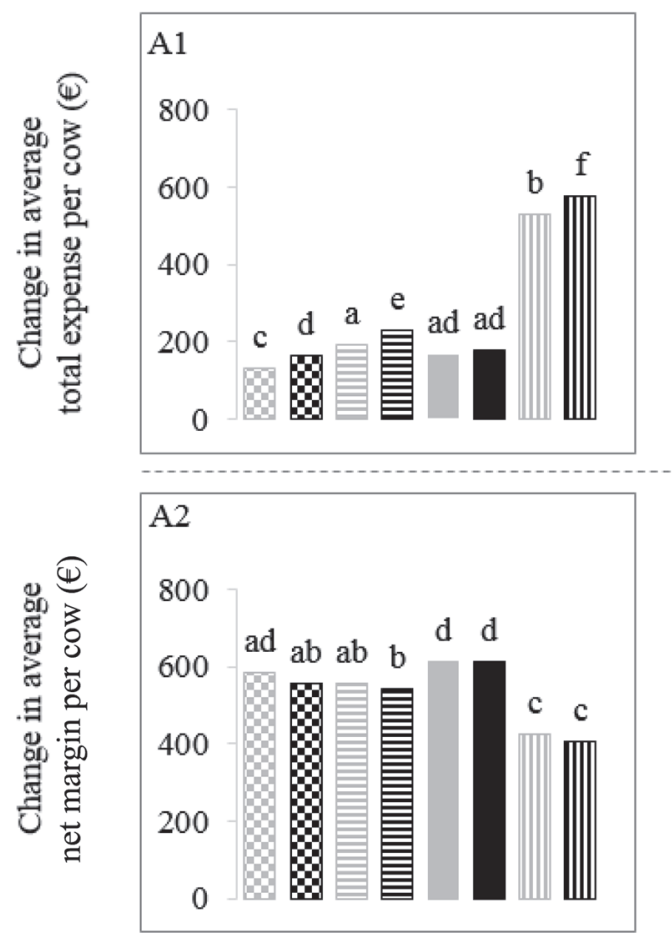

Organic farming system
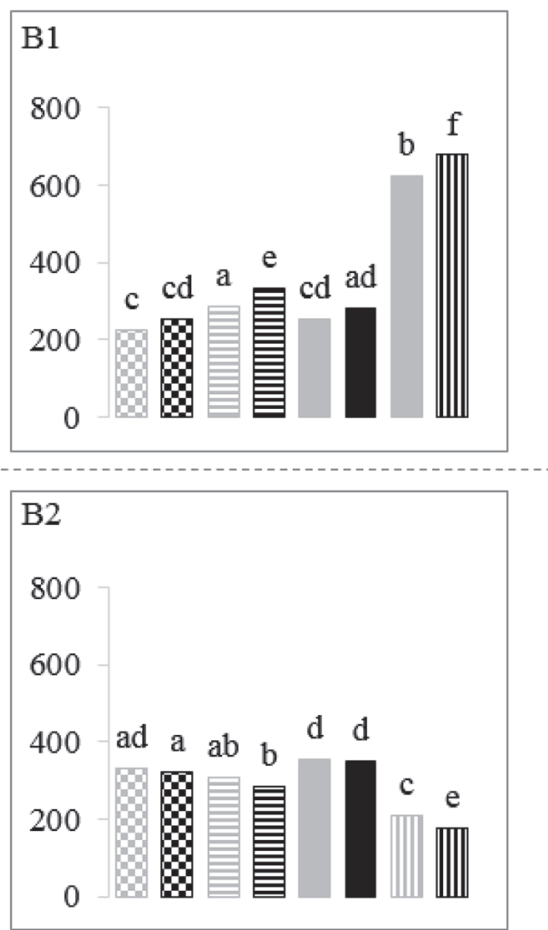

Milk farming system

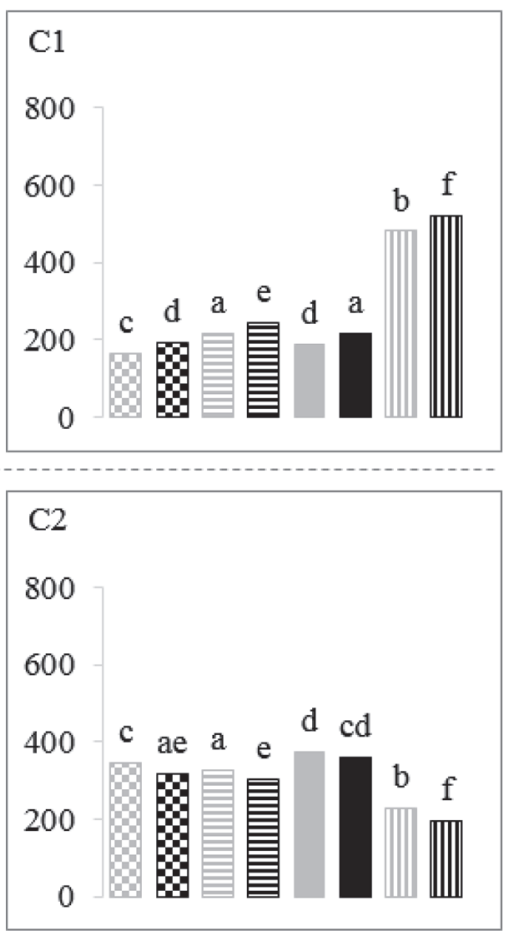

Figure 4. Change (year 10 values minus year 0 values) in average total expense per cow (A1, B1, and C1) and average net margin per cow (A2, B2, and C2). Year 0 is the reference year with no use of female genotyping, sexed semen, or terminal crossbreeding; year 10 is the last simulated year after $10 \mathrm{yr}$ of alternative replacement and genotyping strategy. Averages were calculated over 250 simulation replicates per farming system and per alternative replacement and genotyping strategy. Farming system: Cheese farming system = milk sold to make protected designation of origin cheese (A1 and A2); Organic farming system = organic milk sold to dairy (B1 and B2); Milk farming system = standard milk sold to dairy (C1 and $\mathrm{C} 2)$. Alternative replacement and genotyping strategies: $(\mathrm{P}) \mathrm{NSex}-\mathrm{Cr}=$ no female genotyping, conventional and beef breed semen only; (G)NSex-Cr = female genotyping, conventional and beef breed semen only; $(\mathrm{P}) \mathrm{NSex}-\mathrm{NCr}=$ no female genotyping, conventional semen only; (G)NSex-NCr = female genotyping, conventional semen only; (P)Sex-Cr = no female genotyping, sexed, conventional, and beef breed semen; (G)Sex-Cr = female genotyping, sexed, conventional, and beef breed semen; (P)Sex-NCr = no female genotyping, sexed and conventional semen only; and $(\mathrm{G}) \mathrm{Sex}-\mathrm{NCr}=$ female genotyping, sexed and conventional semen only. Bars with different letters (a-f) differ significantly $(P<0.05)$. 
Table 4. Breakeven price of genotyping (calculated in yr 9 and 10 of the simulation) and maximum investor genotyping price (maximum genotyping price to obtain a nonnegative return on investment $10 \mathrm{yr}$ after starting female genotyping), calculated for each replacement strategy and each farming system simulated

\begin{tabular}{llcc}
\hline & & \multicolumn{2}{c}{ Genotyping price $(€)$} \\
\cline { 3 - 4 } Farming $_{\text {system }}{ }^{1}$ & & \multirow{2}{*}{ Breakeven } & Investor \\
\hline Cheese & Strategy $^{2}$ & 5.3 & 6.5 \\
& NSex-NCr & 18.6 & 26.0 \\
& Sex-NCr & 36.3 & 19.5 \\
& Sex-Cr & 9.9 & 1.9 \\
Organic & NSex-Cr & 17.8 & NA $^{3}$ \\
& NSex-NCr & -5.2 & NA \\
& Sex-NCr & 27.8 & 12.4 \\
Milk & Sex-Cr & 12.4 & 1.1 \\
& NSex-Cr & 4.2 & 8.2 \\
& NSex-NCr & 4.4 & 2.0 \\
& Sex-NCr & 12.8 & 7.9 \\
& Sex-Cr & -1.4 & NA \\
\hline
\end{tabular}

${ }^{1}$ Cheese $=$ milk sold to make protected designation of origin cheese; Organic $=$ organic milk sold to dairy; Milk = standard milk sold to dairy.

${ }^{2} \mathrm{NSex}=$ no use of sexed semen; $\mathrm{Sex}=$ use of sexed semen; $\mathrm{NCr}=$ no crossbreeding with beef breed; $\mathrm{Cr}=$ crossbreeding with beef breed.

${ }^{3}$ Not available; no solution could be found: a positive return on investment was not achievable within $10 \mathrm{yr}$ under the replacement strategy for the farming system considered, regardless of the genotyping price.

field. Hjortø et al. (2015) found that the reproduction management levels of the farm (estrus detection rate and conception rate) affected the benefits of female genotyping. They found that there was no interest in genotyping or using crossbreeding when reproductive performance was poor because the herd always needed to purchase replacement females. Finally, they found a higher gain in genetic merit and higher breakeven price of genotyping with good reproductive performance compared with average reproductive performance. Therefore, results could vary depending on the average reproductive performance of the herd considered and the conception rate achieved. To avoid increasing the complexity of the simulation, this aspect was not considered in our simulations but, in contrast with Hjortø et al. (2015), other factors influencing the probability of fertilization were accounted for, including, for instance, parity, DIM, and production level.

Age Profile of the Herd. Our model favored the replacement of cows by calving heifers in the herd because entrance into the lactating herd was conditioned by the genetic merit of the heifer for total merit, which was usually higher than that for cows. Because younger animals usually produce less milk than older females, this could be seen as a negative point. However, our results showed that even with a younger herd, the average milk yield per cow was always higher in yr 10 than in yr 0. Moreover, this model mimics French Montbéliarde farmers' current practices when they have the choice between culling a cow to calve a heifer and to milk a first-lactation cow or selling a "ready-to-calve" heifer to keep a cow longer in the herd. Even if it seems less profitable, Montbéliarde farmers prefer the former because they know heifers are less susceptible to fertility disorders, mastitis, or other health problem. This practice is also supported by current good market conditions for Montbéliarde cows, sold either to farms lacking replacement or to slaughterhouses as dual-purpose animals.

\section{Use of Sexed Semen Influences Herd Demography}

After $10 \mathrm{yr}$ of simulation, the demographic structure of the simulated herd was similar among replacement strategies using conventional semen only (NSex-NCr) or using sexed semen and terminal crossbreeding (S$\mathrm{Cr}$ ), under all farming systems and with or without female genotyping. When using sexed semen without terminal crossbreeding (Sex-NCr), the number of heifers in the herd and the replacement rate increased in $10 \mathrm{yr}$ because all females could potentially produce a purebred female calf that could one day enter the herd. As heifers have, on average, better genetic merit than cows, the inclusion of heifers in the herd compensated for by cow culling was favored in our model. Although not perfect, our way of modeling heifer selection was closer to the behavior of Montbéliarde farmers than to the heifer selection model of Kaniyamattam et al. (2016), where Holstein female calves were sold at 3 to $4 \mathrm{mo}$ of age. In France, male dairy calves are sold when they are between 8 and $28 \mathrm{~d}$ old. Simulating scenarios such as Sex-NCr, where the number of dairy heifer calves born and bred until ready to calve exceeds the number of replacement heifers needed, may seem extreme. However, this Sex-NCr scenario reflects the current strategy of some farmers who want to guarantee their replacement despite the risk of having too many females, because they know they will be able to sell ready-to-calve Montbéliarde heifers for which the local or international market is usually good. It is also a good illustration of the effect of an excess of replacement heifers on the reduction of a cow's productive life (due to an excess of heifers for replacement) in a commercial dairy herd.

\section{Genetic Gain Is Higher Using Sexed Semen and Female Genotyping}

Semen Type. The highest genetic gain was always obtained for scenarios using sexed semen. Similar results were observed by Hjortø et al. (2015), Kaniyamattam et al. (2016), and Ettema et al. (2017). This result has 2 causes. First, in scenarios without terminal crossbreeding, the use of sexed semen strongly increased 
the number of heifers available for replacement, which increases selection intensity when entering the lactating herd. As expected, this higher selection pressure leads to a higher genetic gain over time. Furthermore, even between strategies with similar replacement rates, such as Sex-Cr and NSex-NCr, the genetic gain over 10 yr was higher when using sexed semen and beef breed semen than only conventional semen. Because sexed semen was used on the best young females (heifers and first-lactation cows) and beef breed semen was used on the worst and oldest cows, the probability of getting female calves from the best females increased and getting offspring from the worst females was avoided (Ettema et al., 2011, 2017; Johnson et al., 2018).

Genotyping. In scenarios combining genotyping and sexed semen, GEBV can be used in mating plans to prioritize high-merit heifers for sexed semen. Our results show that the genetic gain was higher when using GEBV rather than PEBV for selection and mating (although not always significant): increased EBV accuracy leads to a more accurate female selection and therefore to a higher genetic gain. However, the achieved genetic lag between scenarios using GEBV versus PEBV might be greater in reality than in our simulation because here, assumed PEBV accuracies for nonproduction traits were quite optimistic. Kaniyamattam et al. (2016) also found that the average net merit of cows was higher when GEBV were used instead of PEBV to select heifers, after 15 yr of alternative genotyping strategies. Hjort $\varnothing$ et al. (2015) studied the effect on genetic merit and economic parameters of a Danish Holstein herd under several alternatives: different sexed semen strategies at fixed replacement rates with full or partial heifer genotyping and under 3 reproduction management levels (poor, average, and good). After 20 yr of alternative mating strategies, they found a difference in genetic merit of 0.096 SD units of the breeding goal at an average level and 0.137 at a good level of reproduction management, when all heifers were genotyped. Their results are slightly higher than ours, which is likely due to our shorter simulation period, as genetic lag increases over time. In 2017, the average annual genetic gain for total merit index was about 3.5 units $(\approx 0.175 \mathrm{SD}$ of the breeding goal) in the Montbéliarde breed. Therefore, use of sexed semen provided about 1 extra year of genetic gain and use of female genotyping provided about 5 extra months of genetic gain over 10 yr.

\section{Economic Performance}

Revenues. The largest gain in total revenues for all farming systems was with the Sex-NCr scenario because the high replacement rate and the large number of heifers reared led to a high increase in revenues from sales of females. A limitation of our model that would temper this result is that we assumed that animal price did not fluctuate with market saturation. We chose to maintain this assumption for 2 reasons: (1) it was not possible to predict future market variations during the next $10 \mathrm{yr}$, and (2) adding extra variation on price assumptions would have made the results more difficult to interpret. If the market is not saturated, which is the current situation for the Montbéliarde breed in France, and under our price assumptions, we conclude that selling ready-to-calve heifers or cows for culling brings greater income than selling calves.

Costs. Rearing more heifers than needed for replacement also increases total expenses. In their study, Newton et al. (2018) showed that the assumed marginal return for surplus heifers (i.e., sale price minus rearing costs) had a high influence on the benefit of using sexed semen with female genotyping compared with genotyping using conventional semen only. McCullock et al. (2013) modeled 3 different sexed semen strategies: (1) heifers inseminated with sexed semen and cows with conventional semen, (2) heifers and the best cows inseminated with sexed semen and the remaining cows with conventional semen, and (3) heifers and the best cows inseminated with sexed semen and the remaining cows with beef breed semen. They found that using terminal crossbreeding was barely profitable, as this strategy reduced the possibility to sell replacement surplus heifers. Regarding cost variations over $10 \mathrm{yr}$, our results show that introducing genotyping increased total expenses per cow compared with strategies using PEBV only. The highest variation in total expenses per cow between scenarios with and without genotyping was found for the Sex-NCr strategy.

Analysis of Price Sensitivity. McCullock et al. (2013) found that profitability was sensitive to heifer price and price difference between heifer calves and crossbred and male calves. We performed a sensitivity analysis for ready-to-calve heifer price and crossbred calf price (see Supplemental File S5; https://doi.org/ 10.3168/jds.2018-16041). This analysis revealed that farms with intensive production of surplus heifers were the most exposed to market price fluctuations. Because the gap in price between dual-purpose male calves and beef crossbred calves is not large, decreasing the crossbred calf price had a much smaller effect on change in margin over time than decreasing the ready-to-calve heifer price. Ettema et al. (2017) showed that profitability was even more sensitive to heifer rearing costs. Therefore, our conclusion may also depend on price assumptions regarding rearing and reproduction costs for heifers. It is important to stress that even if NSex-NCr and Sex-Cr scenarios have similar replacement rates, 
herds following the Sex-Cr strategy would produce diversified animal products (ready-to-calve heifers, crossbred calves, dairy male calves), which would be an advantage in fluctuating market conditions. This was due to the higher rearing and reproduction costs when producing many female calves. Our results underline the key role of replacement strategy and farming system on the genetic and economic benefit of female genotyping in commercial herds when comparing variation in margin per cow among farming systems.

\section{Maximum Female Genotyping Price}

Breakeven prices (maximum genotyping price under which routine female genotyping is economically valuable) and maximum investor prices (maximum genotyping price such that the female genotyping costs are refunded within $10 \mathrm{yr}$ of investment) of genotyping were always lower than our assumption of $€ 40$ per genotyping test. However, this assumption of a fixed genotyping price is quite pessimistic, as genotyping price is expected to continue to decrease due to expanding market technology improvements.

In 3 of 12 situations, maximum investor prices could not be calculated, meaning that it was not possible to obtain a positive return on investment for female genotyping within $10 \mathrm{yr}$ at a discount rate of $4 \%$. For the other 9 situations, the investor genotyping price is the maximum genotyping price to obtain a positive return on investment $10 \mathrm{yr}$ after starting female genotyping on young heifers. The maximum investor genotyping price could always be calculated for the Sex-Cr strategy, meaning that this strategy could bring a positive return on investment after $10 \mathrm{yr}$ of use of female genotyping, only if the genotyping price was less than or equal to $€ 19.5$ for the cheese farming system, €12.4 for the organic farming system, and $€ 7.9$ for the milk farming system.

Across all farming systems, Sex-Cr strategy was the most profitable one as it provided the highest genotyping breakeven price. The use of sexed semen enables a better choice of females that give birth to the next generation, bringing extra genetic progress on production traits, which in turn increases income. Besides, the use of crossbreeding with beef breed semen limited the extra rearing and reproduction costs of producing too many replacement heifers. Negative breakeven genotyping prices, observed for OrgSex-NCr and MilNSex-Cr scenarios, indicate that these strategies lead to losses when combined with genotyping and should be avoided. Boichard et al. (2013) estimated the breakeven genotyping price to be from $€ 48$ to $€ 53$ $10 \mathrm{yr}$ after adopting female genotyping, which is more optimistic than our results. In Denmark, Hjortø et al. (2015) assessed the genotyping breakeven price in a Danish Holstein farming system similar to our milk farming system. In their 20-yr stochastic simulation study, they measured the effect of different genotyping and sexed semen strategies on operational return and genetic gain. Their breakeven genotyping prices ranged from $€ 21$ to $€ 37$ in a farming system similar to our milk system. However, they calculated the genotyping breakeven price after 16 to $20 \mathrm{yr}$ of simulation, whereas we calculated genotyping breakeven prices after 9 to $10 \mathrm{yr}$ of alternative genotyping strategies. As shown by Boichard et al. (2013), breakeven genotyping price increases with time because the additional genetic gain obtained with the use of genotyping is cumulative over time. Therefore, the difference observed between our results and theirs was consistent with the fact that our genotyping breakeven prices would have been higher, albeit somewhat artificially, if we had simulated the herd for 10 more years.

\section{CONCLUSIONS}

From a genetic point of view, systematic female genotyping is a valuable option at the herd level for the 3 farming systems considered in this study and whatever replacement strategy is adopted. As hypothesized, female genotyping and the use of sexed semen accelerated overall genetic gain, in general. Herd net margin increased the most in farming systems with a high milk price. Overall, the economic benefit of genotyping females, combined or not with a change in mating strategy, depended on the farming system, the market opportunities, and the investment capacity of each farm, even if the benefit of genotyping and increasing selection capacity was clear in terms of genetic gain. The genotyping breakeven price (maximum genotyping price under which routine female genotyping is economically valuable) was low, from $€ 5.3$ to $€ 36.3$ for cheese, from - $€ 5.2$ to $€ 27.8$ for organic, and from $-€ 1.4$ to $€ 12.8$ for milk farming systems. However, it would have been higher after a longer simulation period. The scenario combining the use of sexed semen and use of beef breed crossbreeding was the only one that allowed for a return on investment within $10 \mathrm{yr}$ in all the farming systems, for genotyping prices of $€ 19.5$, $€ 12.4$, and $€ 7.9$ in the cheese, organic, and milk farming systems, respectively. The highest breakeven price for genotyping was always reached for the scenario combining the use of sexed semen and the use of beef breed crossbreeding. It should be noted that this value did not account for other benefits of genotyping (e.g., full parentage knowledge, more accurate mating plans, management of genetic defects). Because genotyping price is expected to continue to decrease over time, in- 
vestment in female genotyping will be profitable at the farm level in combination with an appropriate change in mating strategy, especially with use of sexed semen.

\section{ACKNOWLEDGMENTS}

Marie Bérodier is recipient of a CIFRE PhD grant jointly funded by MO3 company (MO3, Ceyzériat, France) and French "Agence Nationale de la Recherche et Technologie." The authors acknowledge the MO3 company for providing technical support (field experts, notably P. Andraud, L. Balberini, F. Dubief, P. Dubois, G. Fayolle, N. Gaudillère, and B. Humbert). The authors acknowledge INRA Nantes (BIOEPAR, INRA, Oniris, Nantes, France) for providing the simulation software. The authors also acknowledge the two anonymous reviewers for their remarks and suggestions that improved this paper, in particular regarding the economic analysis. The authors thank François Bareille (University of Bologna, DISTAL, Italy) for his useful advice on the economic aspects of the paper.

\section{REFERENCES}

Boichard, D., R. Dassonneville, S. Mattalia, V. Ducrocq, and S. Fritz. 2013. All cows are worth to be genotyped! Interbull Bull. 47:256260

Boichard, D., F. Guillaume, A. Baur, P. Croiseau, M. Rossignol, M. Boscher, T. Druet, L. Genestout, J. Colleau, L. Journaux, V. Ducrocq, and S. Fritz. 2012. Genomic selection in French dairy cattle. Anim. Prod. Sci. 52:115-120. https://doi.org/10.1071/AN11119.

Coulon, J. B., L. Perochon, and F. Lescouret. 1995. Modelling the effect of the stage of pregnancy on dairy cows' milk yield. Anim. Sci. 60:401-408.

Dezetter, C., N. Bareille, D. Billon, C. Côrtes, C. Lechartier, and H. Seegers. 2017. Changes in animal performance and profitability of Holstein dairy operations after introduction of crossbreeding with Montbéliarde, Normande, and Scandinavian Red. J. Dairy Sci. 100:8239-8264. https://doi.org/10.3168/jds.2016-11436.

Ettema, J. F., S. Østergaard, and M. Sørensen. 2011. Effect of including genetic progress in milk yield on evaluating the use of sexed semen and other reproduction strategies in a dairy herd. Animal 5:1887-1897. https://doi.org/10.1017/S175173111100108X.

Ettema, J. F., J. R. Thomasen, L. Hjortø, M. Kargo, S. Østergaard, and A. C. Sørensen. 2017. Economic opportunities for using sexed semen and semen of beef bulls in dairy herds. J. Dairy Sci. 100:4161-4171. https://doi.org/10.3168/jds.2016-11333.
Hjortø, L., J. F. Ettema, M. Kargo, and A. C. Sørensen. 2015. Genomic testing interacts with reproductive surplus in reducing genetic lag and increasing economic net return. J. Dairy Sci. 98:646-658. https://doi.org/10.3168/jds.2014-8401.

Hohenboken, W. D. 1999. Applications of sexed semen in cattle production. Theriogenology 52:1421-1433.

Holden, S. A., and S. Butler. 2018. Review: Applications and benefits of sexed semen in dairy and beef herds. Animal 12:s97-103. https: //doi.org/10.1017/S1751731118000721.

INSEE. 2019. Taux d'inflation en 2018, données annuelles de 1991 à 2018. Accessed Apr. 26, 2019. https://www.insee.fr/fr/statistiques/ 2122401\#tableau-Donnes.

Johnson, T., K. Eketone, L. McNaughton, K. Tiplady, J. Voogt, R. Sherlock, G. Anderson, M. Keehan, S. R. Davis, R. J. Spelman, D. Chin, and C. Couldrey. 2018. Mating strategies to maximize genetic merit in dairy cattle herds. J. Dairy Sci. 101:4650-4659. https://doi.org/10.3168/jds.2017-13538.

Kaniyamattam, K., M. A. Elzo, J. B. Cole, and A. Vries. 2016. Stochastic dynamic simulation modeling including multitrait genetics to estimate genetic, technical, and financial consequences of dairy farm reproduction and selection strategies. J. Dairy Sci. 99:81878202. https://doi.org/10.3168/jds.2016-11136.

Le Mézec, P. 2016. Le point sur l'utilisation de semence sexée en 2015. Institut de l'Elevage. Accessed Jun. 12, 2018. http://idele.fr/ fileadmin/medias/Documents/0016203025_IA2015_semsex_hors _emp.pdf.

Lenth, R. 2018. emmeans: Estimated Marginal Means, aka LeastSquares Means. R package version 1.2.2. https://CRAN.R-project .org $/$ package $=$ emmeans

McCullock, K., D. Hoag, J. Parsons, M. Lacy, G. Seidel, and W. Wailes. 2013. Factors affecting economics of using sexed semen in dairy cattle. J. Dairy Sci. 96:6366-6377. https://doi.org/10.3168/ jds.2013-6672.

Newton, J. E., B. J. Hayes, and J. E. Pryce. 2018. The cost-benefit of genomic testing of heifers and using sexed semen in pasture-based dairy herds. J. Dairy Sci. 101:6159-6173. https://doi.org/10.3168/ jds.2017-13476.

Norman, H. D., J. L. Hutchison, and R. H. Miller. 2010. Use of sexed semen and its effect on conception rate, calf sex, dystocia, and stillbirth of Holsteins in the United States. J. Dairy Sci. 93:38803890. https://doi.org/10.3168/jds.2009-2781.

Pryce, J., and B. Hayes. 2012. A review of how dairy farmers can use and profit from genomic technologies. Anim. Prod. Sci. 52:180-184.

R Core Team. 2018. R: A language and environment for statistical computing. R Foundation for Statistical Computing, Vienna, Austria. https://www.R-project.org/.

Weigel, K. A., P. C. Hoffman, W. Herring, and T. J. Lawlor Jr.. 2012. Potential gains in lifetime net merit from genomic testing of cows, heifers, and calves on commercial dairy farms. J. Dairy Sci. 95:2215-2225. https://doi.org/10.3168/jds.2011-4877.

Wood, P. D. P. 1967. Algebraic model of the lactation curve in cattle. Nature 216:164-165. 